\title{
Engaging Indigenous Communities in the Classroom: The Eastern Shawnee Tribe of Oklahoma and Miami University
}

\author{
Robin Dushane, Sandra Garner, Casey Smitson, Jason Banks
}

\begin{abstract}
This article explores the concepts of community driven research and experiential learning in the context of partnerships between universities and indigenous communities. Specifically, this article examines the successes and challenges of Miami University's partnership with the Eastern Shawnee Tribe of Oklahoma (ESTOO). Taking a dialogic approach, a professor, two students and a tribal leader, reflect on their experiences within the partnership and provide insight into how partnerships between universities and indigenous communities might develop, function, and serve both students and community members.
\end{abstract}

KEYWORDS community driven research; experiential learning; Indigenous communities

In 1969, Vine Deloria, Jr., offered a powerful critique of academic research on Indigenous cultures as he drew attention to the negative impacts on the very communities being studied. His now canonical chapter, "Anthropologists and Other Friends" in Custer Died for Your Sins: An Indian Manifesto, clearly articulated the complicity of researchers in the continued colonization of Native American communities (Deloria, Jr., 1969). Since that time, scholars such as Linda Tuhiwai Smith (1999) have proposed guidelines for decolonized methodologies, and many scholars, both Indigenous and non, have sought to engage in more equitable, sensitive, and collaborative research relationships with the communities they study.

However, little focus has emerged regarding teacher/scholar models in which students contribute on the ground in Indigenous communities. How can scholars incorporate culturally sensitive approaches, theory, and methods into classrooms, frequently filled with non-Native students who have little or no knowledge about the histories and cultures of Indigenous communities and, to be honest, have little desire to learn (at least in regards to the numbers necessary to fill classes within the institutional structure)? Two programs have provided inspiration and demonstrate the breadth of what teaching models may look like: the Myaamia Center (Miami University) and the Cherokee Study Abroad program (University of North Carolina).

Since 2012, a course that is part of the core curriculum for American Studies majors (AMS), at Miami University (Oxford) has provided community-driven research and products for the Eastern Shawnee Tribe of Oklahoma (ESTOO). Each year the tribe identifies projects needed for their community, and students collaborate with tribal members to complete these 
assignments. Student research has resulted in an article written for the tribal newsletter, The Shooting Star, which has a readership of more than 3,000, a short film about the tribe, a collection of Shawnee myths, and in 2014 a service learning, summer workshop to support the ESTOO's summer youth culture camp was added.

This article is a collaborative effort that reflects on the successes and challenges of this type of experiential, service learning from three perspectives - that of the Indigenous community (ESTOO), the teacher/scholar, and two students who have been involved in a variety of projects over two years (2013-2015). In the first section, we'll provide some background about the institutions involved, describe the projects, and introduce the collaborators involved with this article. The second section of this paper is a dialogic exchange from the three perspectives. Finally we'll conclude with a summary of what we've learned from this process and offer our focus for future efforts.

\section{Background, Description, and Introduction}

There is a long, rich history of Native presence in present-day Ohio. For millennia, indigenous cultures such as the so-called Adena, Hopewell, and early Woodlands era people to historic tribes such as the Shawnee have called this geographical location home. When Ohio became a state in 1803, there was still a significant Native presence in the state. After the passage of the Indian Removal Act in 1830, tribal groups were removed, during a series of waves that lasted from the early 1830s through the late 1840s, to "Indian Territory." As a result of this history, in spite of the fact that there is a Native population in Ohio, for today's $21^{\text {st }}$ century university student in Ohio, Native presence is invisible. There are no federally recognized tribes in the state. In this historical context it is not surprising that for those students who attend Miami University, Native Americans are invisible or a people of the past.

Miami University was founded in 1809 and is the oldest university in the state of Ohio. It is a public university located in a rural area about thirty-five miles northeast of Cincinnati, which at present (2015) serves more than 15,000 undergraduate students. For decades the university has been touted by students and alumni as "the Ivy league of the Midwest" and current marketing campaigns promote the university as a "Public Ivy League" institution. This is an important context as it speaks to the sense of privilege and lack of diversity that marks the overall student body. Learning about the original inhabitants, the Shawnee, has the potential to broaden these students' understanding.

After the Treaty of Greenville in 1795, many Shawnee began moving west, but some remained in Ohio, and in 1817 three reservations were established in the northeastern part of the state: Hog Creek, Wapakoneta, and Lewistown. The latter reserve has a direct ancestral relationship with the contemporary tribe ESTOO. In September 1832, the Shawnee residing on these reserves began the long walk to Indian Territory. The inhabitants of Lewistown arrived at the site of their new home in Indian Territory in December 1832. Thirty percent of the group died during the removal process.

Today ESTOO tribal membership exceeds 3,200 members. The tribal complex remains at the site of their removal destination near the Oklahoma-Missouri line in Ottawa County,

Engaged Scholar Journal: Community-Engaged Research, Teaching and Learning 
Oklahoma. The tribe's three casinos, travel center, hotel and administrative offices employ over 600 people and each of these facilities is owned outright by the Tribe. Current land holdings of the ESTOO exceed 1,700 acres. These holdings are all within the tribe's original reservation, as assigned in 1832. The nine buildings which house the administrative staff of the tribe have all been constructed since 1980 to the present. The Administrative Offices of the ESTOO include twenty-five separate departments.

The primary department which serves as the contact point for the relationship between the service learning, experiential community outreach classes taught at Miami University is the Cultural Preservation Department whose mission is: "Promoting knowledge of historical and participation in Contemporary Shawnee Culture." Robin Dushane serves as ESTOO's Tribal Historic Preservation Officer (THPO) and has been employed by the Tribe for ten years. She began as the Cultural Preservation Director, re-establishing the department after an absence of ten years. Her many accomplishments include arts revitalization, directing the NAGPRA office, language preservation, monthly cultural events, directing the Tribal Museum, and establishment of the Tribal Historic Preservation Office (funded through the Department of Interior). She is a tribal spouse of seventeen years. As the THPO for ESTOO her motivation for seeking a partnership with academia was to pursue further assistance with tribal research and support, vis-à-vis camp counselors for the ESTOO youth summer culture camp.

Sandra Garner, an assistant professor in American Studies, serves as the primary contact person from Miami University and teaches the research course and summer workshop that are involved in this collaborative relationship. A graduate of The Ohio State University, her broad research and teaching interest focuses on culture, specifically issues of identity, belonging, difference, as well as, intercultural awareness and understanding-particularly the construct of Indigenous identities emergent from settler colonial contexts. Her pedagogical approach seeks to engage students in community outreach through experiential learning activities and the development of community-driven research projects. To date, her research has focused on Lakota on the Rosebud Reservation, where she was a tribal spouse for more than 20 years. She came into this working relationship with little specific knowledge about Shawnee history or culture, but was inspired to offer assistance as a result of meeting ESTOO Chief Glenna Wallace.

Two former students that have been associated with the Miami University courses also collaborated on this article in order to provide a student perspective of the projects. Jason Banks is a recent graduate of Miami University (2015) receiving his BA in Political Science with minors in Management and Latin American Studies. As an undergraduate student, Bank's first introduction to ESTOO came as a result of a course he took with Dr. Garner. His team's final research paper on Quatawapea (Col. Lewis), a Shawnee chief instrumental in founding the Lewistown reservation in Ohio, was published in the ESTOO's newsletter, The Shooting Star. He has traveled to Oklahoma on three occasions, on two of which he served as a counselor in the Summer Youth Culture Camp. Banks plans on pursuing a graduate degree in Public Policy.

Casey Smitson graduated from Miami University (2014) with a double major: an honors distinction in American Studies and German. Smitson served as an Undergraduate Associate 
for the American Identities course (2014) and developed a pilot summer camp program with the Eastern Shawnee as part of her senior honors thesis project. After graduation, she spent a year living and teaching in Düsseldorf, Germany as a Fulbright English Teaching Assistant. She is currently back at Miami University pursuing a master's degree in Student Affairs in Higher Education.

The collaborative research engagement between ESTOO and Miami University is beginning its fourth year and has involved two courses, as well as a senior honors thesis, and several independent studies. AMS (American Studies) 301 titled "American Identities: Community-driven Research" is a mid-range required course for AMS majors that focuses on research methods and analyses used in the field of American studies. In addition to teaching students to formulate and implement a research plan, the course is designed to build an ethos of teamwork and to develop projects that speak to different audiences. Each year the ESTOO communicates ideas about research projects, and students present their final projects to the tribe. All research materials and final projects are donated to the tribe.

In 2015, a summer travel away workshop: "Engaging Shawnee Youth" was officially offered for the first time. The summer workshop was based on a model developed by Smitson as part of her thesis the previous year. In 2014, three students traveled to Oklahoma to implement the model as a trial. This was a volunteer service activity for these students. In 2015, the workshop received official course approval and five participated in a ten day long trip to support the ESTOO's Youth Culture Camp. In the remainder of this article, we (Dushane (RD), Garner (SG), Banks (JB), and Smitson (CS)) reflect on these projects from a variety of lenses: tribal, academic, and student. We begin by offering our initial impressions, a discussion of specific aspects of the various projects, and concluding with what we see as the strengths and weakness as we plan for the future.

\section{Initial Impressions}

Robin Dushane: I knew I needed assistance and that I needed help from an academic institution. Establishing a long-term, consistent relationship has been an important part of this process. We took the necessary time and effort to establish a relationship, it was not something that we accomplished and knocked out real fast. It helps to build trust. Establishing a regular routine of communication is working very well. Whenever we have something to be talked out, we are able to do that and we are getting better at it. For people who don't see each other but one week a year we have good communication. This builds a bridge of trust; it made me realize that I'm working with dependable people. I wouldn't have felt good about it if I was just working with a professor that didn't have experience working with Native cultures, that was the key, I think. You always listen to us. You don't tell us what we need. This relationship was a godsend and I'm really looking forward to seeing where it goes.

Sandra Garner: Two goals motivated me to initiate this in partnership. First was a strong desire to contribute and support Native communities with projects they identify and define as important. Second was a desire to model a pedagogical approach that understands student 
learning about different cultures is limited by classroom-only education and that students value the experience of producing products that have real-world meaning. Experiential learning is a powerful tool to understand issues of power, difference, and other world-views.

I went into this collaborative process knowing that there would be a learning curve as I worked to build a level of trust with the community - trust both in the sense that we would listen to the community's needs and feedback, but also that we are dependable and would consistently return over time. I did not anticipate the learning curve in two regards. First, although I have a great deal of experience working with Native communities and have a strong foundation regarding Native American history and culture, I had little knowledge specific to ESTOO, which may be one of the most difficult tribes to trace from a historical perspective. Four years later I'm only beginning to get a handle on the basics. This relates to the second issue, how to provide students with the necessary foundational knowledge and skills to actually conduct meaningful research for the tribe. I have depended greatly on student feedback in order to shape course content. It is only after four years of reworking the syllabus, that I feel I have struck a good balance and this year will replicate the initial readings meant to contextualize the projects that the students will develop.

Jason Banks: As a recent graduate of Miami University, I never anticipated my research in Dr. Garner's class to have had such a strong impact on the lives of others. Learning how to produce adequate research materials has definitely been a journey. Prior to taking AMS 301 (fall 2014), my inexperience with research methods meant I did not have the skills to uncover historical information pertaining to ESTOO. My former experiences and expectations with research were from a naïve point of view, since my only understanding of research was finding information and stating my conclusions. I soon learned, research could take on a life of its own, especially when I realized my contributions not only affected how well I performed in the classroom, but more importantly how my research affected those outside of the classroom. Researching ESTOO provided me with a unique experience to work independently on numerous projects and allowed me to engage in experiences that I never thought I would appreciate so much.

Casey Smitson: Working with the Eastern Shawnee Tribe of Oklahoma was a truly transformational learning opportunity that challenged me to grow both personally and academically. Serving as an Undergraduate Associate (UA) for Dr. Garner's AMS 301 course and then later partnering with ESTOO as part of my senior thesis introduced me to vibrant community and challenged me to think critically about service and what it entails. Through these experiences, I developed a better understanding of the Eastern Shawnee and their stories and graduated with improved research skills, ability to communicate, and confidence in my ability to respectfully serve and contribute to diverse communities. 


\section{AMS 301: "American Identities: Community Driven Research"}

Sandra: When I was first asked to teach this course, the title was "Methods and Practices in American Studies" and student learning objectives included developing and implementing a research project. It is a preparatory course for senior capstone projects. The idea of developing research projects that would contribute to ESTOO provides students the opportunity to think through a research plan and create projects in multiple media that address a variety of audiences. Each year the projects identified by the tribe differ and after the 2013-2014 school year I switched and started teach the course during spring semester.

This course has historically had low student enrollment. This is helpful for managing this type of classroom, but makes institutional buy-in difficult to maintain. After the first year I taught the course, the name was changed to "American Identities" and the learning objectives remained unchanged. Faculty thought the name change would generate greater student interest and indeed it does. Yet, it has created some confusion for students registering for the course. Below is a brief description of the projects to date.

Year 1 (FA 2012): Students produced posters that summarized research topics they chose. Chief Wallace came to campus at the end of the semester and students presented their research to her.

Year 2 (FA 2013): Four projects were identified by Chief Wallace and the THPO, Robin Dushane. These included: 1) identify and collect Shawnee myths and legends; 2) create a google map of the removal route of the Shawnee from Lewistown (Ohio) to Oklahoma; 3) research and write a biography of a Shawnee Chief (Quatawapea, Col. Lewis). Lewis was instrumental in the formation of the Shawnee reserves in Ohio and Lewistown was named for him; and 4) create a brief film about Shawnee history geared toward a general audience. Year 3 (SP 2015): Three projects were identified: 1) revise the film after feedback from the tribe; 2) biographical research on early Shawnee leaders in Oklahoma; and 3) planning and marketing the Summer Travel Away workshop to support ESTOO’s Youth Culture Camp.

Jason: I selected Dr. Garner's AMS 301 course with little prior knowledge about Native cultures, minimal research experience, and an unclear concept of community-driven research. I chose to take the class because it fit well into my schedule and because I was curious about American Studies at Miami. I quickly realized that I was in for much more than I had bargained for. When I first saw the course syllabus, I was shocked by both the course workload and the expectations surrounding the research component of the class. I immediately considered dropping the class. After Dr. Garner explained the various projects and their significance to ESTOO, however, I decided to stay in the class. I was intrigued by the idea of doing research for a community instead of for the sole purpose of achieving a letter grade. My interest surrounding the projects quickly lead to excitement, and I became more willing to tackle the unknowns of the course and the daunting workload. Knowing that my work would serve ESTOO motivated me to take on new challenges and to fully commit to the class.

Despite my initial enthusiasm, the research proved challenging, and I discovered that my research skills needed to improve in order to retrieve the information requested by the tribe. 
The expectation to do original research meant that I was required to collect and synthesize information to tell the story of a historical figure that had never been told before. Thankfully, I was not alone in this process; I had the support of the three other students in my group and of Dr. Garner, who was always there to offer words of wisdom, assistance, and reassurance. She taught me to research by allowing me to stumble and then try again. This sometimes meant that research was more time consuming and strenuous than it should have been, but the extra effort was always worth it. Each obstacle that I encountered helped me to better understand research and provided me with the opportunity to better learn how to discover, interpret, and revive historical information. Dr. Garner understood that research is best learned by doing. She provided guidance but not answers, allowing me to develop a connection to my research and to appreciate and discover on my own how research functions.

Casey: My initial sense of detachment from the Eastern Shawnee and the projects set for the AMS 301 (2014) course changed when I went to visit the Eastern Shawnee in Oklahoma with Dr. Garner in preparation for the class. In Oklahoma, the Eastern Shawnee welcomed us as honored guests. We stayed in the Chief's home, were given personal tours of the tribal facilities, spoke with tribal leaders, and were invited to participate in community dinners and Shawnee language courses. These small glimpses of ESTOO life, introduced me to a dynamic community mobilizing itself to rediscover its culture, relearn its language, and assert its relevancy in the modern world. I left Oklahoma with a new understanding of ESTOO and with an excitement for the class and the opportunity to learn more about the ESTOO story.

When classes began, Dr. Garner and I had the task of communicating the importance of partnership and our excitement for it to a class of students who, like myself, had very little to no knowledge of Native cultures and communities. The class was small to begin with, but became even smaller after several students saw the rigorous syllabus and chose to drop the class. The student groups and I were not entirely sure of how to approach a class and the partnership with ESTOO and were uncomfortable with this uncertainty. Once the projects began to materialize, however, we began to acknowledge our experience, research skills, and overall ability to contribute. As a result, we were able to locate, organize, and present historical materials to ESTOO, which they will use to help tell their story of struggle, survival and modern resurgence. Serving ESTOO empowered us to identify our ability and responsibility to be agents of social change and to understand research as a skill that can be used to serve and energize diverse communities.

Sandra: Casey and Jason's comments are an affirmation for me in that they confirm my initial presuppositions about the course from a student perspective. Certainly the two do not represent all of the students who have participated in the course, and many are turned off by the amount of labor they perceive is required. Casey talks about the rigor, but in reality the readings and short response papers are no more onerous than those in other courses I teach. What does differ, however, is that in order to succeed the student must be able to conceptualize and complete a project that has a "real-world" audience and implications. In 
order to do so, the student must be self-motivated and be able to work independently. While I think these are necessary skills for the working world, they are not frequently implemented at the university level.

Jason points to an issue that I face every time I teach this course. Research and critically evaluating sources is hard work. I do provide guidance in ways to approach the research process and work to communicate the importance of the thorough documentation of one's research. It is a lesson that many of us in academia have learned the hard way. You learn by doing and making mistakes. I'm heartened that Jason is reflective about this and those students who follow through with their projects have their "aha" moments. The sense of responsibility that comes from this collaborative relationship with the tribe does, as we see from the examples of these two students, have transformative potential. I'd like to reflect now on the specific projects that have been accomplished through this course.

Year 1-Robin: The posters were a wonderful starting point, a kick off for collaboration. The posters were helpful, we displayed two of them in our museum, but apart from that they were used rather minimally. Although we did not use the posters extensively, they were what we needed to engage in a small scale project and they helped us to focus on future projects. The first iteration of the course was more about an exercise of the partnership than the products produced, it was during the second and third years that we were able to do some focused planning together.

Sandra: I couldn't agree more with Robin. In fact, I was a bit embarrassed by the projects produced the first year, the quality of research was superficial and the posters not particularly good. But as Robin notes, it was the process that was beneficial.

The high point for me that semester was watching the students present their work to Chief Wallace. An educator herself, Chief Wallace was engaged and patient with the students and they learned a great deal from her. It was not until this moment that they really grasped that their work had an application in the real world. During the first year, to build a foundation for the project I chose readings about decolonizing research methods, practices, and the power of knowledge. Student feedback showed that this did not provide enough of a framework about the Shawnee specifically and I made major revisions the second year the class was offered.

Year 2--Robin: During the second year the projects were more focused and more useful to us. We were just so overwhelmed and so pleased that the projects were getting better and that we had products in our hands. The Colonel Lewis project and the collection of myths were the strongest projects from the second year. We published an article on Captain Lewis in our Shooting Star newsletter and used a small portion of the project to help us get started on our history grant application. In this way, the initial student research projects turned into bigger research projects. We read myths at our winter gathering and since the reading, people have become more interested in traditional stories and presenting them.

$S G$ : There was a huge improvement the second year, and two of the four projects contributed significantly to tribal efforts. The class presented their projects to tribal employees via a Skype

Engaged Scholar Journal: Community-Engaged Research, Teaching and Learning 
session, and it was great for the students to hear feedback from a number of tribal members. It was heartening for me to attend the tribe's winter gathering in January 2015 and hear some of the Shawnee stories collected by students told at the event. The publication of the Lewis article in the tribe's newsletter was also an exciting, unanticipated bonus for the students who worked on that project.

Two of the projects were not as helpful. One group developed a google map that traced the tribe's removal route from Lewistown to Oklahoma. While the tribe has not directly used this project yet, it may still be of some future value. The fourth project, a brief film about the ESTOO, was admittedly not great. But it was helpful in that it gave us feedback from the tribe and laid the groundwork for a re-envisioned film the following year. To provide a framework for the students (based on student feedback from the previous year) I assigned materials that were Shawnee specific. This was the other extreme and based on that year's student feedback I reworked the initial readings for the third year's project.

Year 3--Robin: The third year was when everything stepped over the top. The video that one of the student groups produced was really something special. We shared the video at our community wide annual event called the Elder's Breakfast during our annual powwow. The event was attended by 250 people. What is different about this event is that many people arrive from all over the United States to come home. These are members that aren't local community, they come from afar. We have members all over the United States, but they don't come around but once a year. Everyone really appreciated that university students had taken interest in their community. The audience felt that we were important enough that college students came to make a video, and it was good. It is hard to express the impact that the video made on the community; it evoked a sense of pride. This whole processes, proliferating our history, when people outside the community are interested in our history, it gives more incentive to our people to learn their own history.

SG: The projects this year were exceptional, particularly the short film developed by the students. It is important to emphasize that the work on this film would not have resulted in such a great project, had students the previous year not developed a film. We were able to learn from the mistakes of the first year. For example, one area that was weak was in regards to the script and voiceover. The first year students provided the voiceover and did not adequately pace themselves--sometimes speaking too fast and at other times too slow. This year a professional offered his services and provided the voiceover for the script. It worked very well.

Another area that I changed going into the year's projects (based on student feedback) was setting the groundwork through initial readings. After three years I think I've finally hit on a combination that works. The students spent four weeks reading materials that provided a broad Native perspective on important issues such as language, history, sovereignty, land, "religion" and storytelling. Then each group spent two weeks reading Shawnee specific materials that related to their group projects. This seemed to work and I'll follow this approach in next year's projects.

There were two additional projects that came out of Year Three's class. One group 
researched tribal leaders who had signed treaties and were referred to as chiefs during the early post-removal years. While they did not find anything to substantially add to what the tribe already knew, they were able to compile the sources into one location. The third group were assigned to the project of working with the tribe to plan the summer youth culture camp and to market the summer workshop to Miami students. The camp is described in more detail below.

\section{Summer Workshop: Engaging Summer Youth}

Robin: Camp couldn't have been done if I hadn't had assistance. We used to put on a small camp program, but we did not have many resources or campers. We only had two staff members and eight campers participate. At the beginning, I didn't realize how beneficial working with Miami would be to us. The camp experience has been elevated by the relationship; we are now able to have overnights and have more activities. Having organized activities and having a schedule were helpful. This partnership_-producing a camp shaped by ESTOO goals and Miami's help achieving these goals—is working.

Casey: After the AMS 301 course concluded, I felt a connection to ESTOO and knew that I wanted to continue working with the tribe. I was particularly interested in learning how I could serve ESTOO youth. Looking back on my trip to Oklahoma, I remembered being struck by how the youth were not only learning their language, history, and culture but also applying these lessons to their daily experiences. Moved to support ESTOO youth, I approached ESTOO about the possibility of partnering with the tribe to create a culturally relevant summer camp program for my senior thesis. I proposed the creation of summer program aimed to provide a place for ESTOO youth to build community and relationships, learn about their culture, and to work on further discovering for themselves what it means to be Shawnee in a modern world.

The process of bringing the program to fruition was much more difficult than I ever imagined. Facilitating communication over the phone across both culture and distance proved to be particularly challenging. Although I regularly communicated with Robin Dushane, two tribal elders, and Dr. Garner, we often struggled to reach consensus on decisions regarding the program structure. Much of this difficulty stemmed from the fact our roles within the group were never clearly defined. This struggle was frustrating for me. I spent an enormous amount of time on the project, and sometimes had to check myself from the idea that the camp program was "my project." The camp program belonged to ESTOO, and it was important for me to remember that just because I invested a significant amount of time on the project did not mean that I knew best. It was through this process that I truly came to understand community driven service. The project was not about me, it was about ESTOO youth.

Sandra: What Casey does not mention here is that she also honed her diplomacy skills during her work on the planning phase. She had to negotiate conference calls with Robin in Oklahoma and the elders, who were going to run the "culture" programming and live

Engaged Scholar Journal: Community-Engaged Research, Teaching and Learning 
on the west coast. All of those involved had very different visions of how the camp would work. Robin also had to negotiate these different participants who came to the process with very different backgrounds and motivations.

\section{Implementation over Two Years}

Casey: The implementation of the 2014 Culture Camp pilot was far from perfect, but was both fun and productive and represented a good first attempt. The program was successful in that it provided twenty ESTOO youth, ages 7-14, with a place to build relationships and to learn about and engage with their culture and identities. The campers practiced archery, played lacrosse, built a traditional housing structure, and assisted in preparing a meal from a threesisters garden. Shortcomings included our failure to adequately staff and logistically organize the program which exhausted the counselors and detracted from the campers' experience. Further, some of the activities emphasizing Native worldviews and themes also fell flat. Thankfully, the partnership continued after I graduated and Dr. Garner and her AMS 301 course were able to implement a much improved program the following summer.

Robin: I wanted our tribal elder to oversee and help produce the schedule and oversee the activities. Sande came to me and said that she thought that Casey was capable of more of a leadership role. We adjusted and compromises were made. Casey was allowed more voice but the elder continued to offer input. The fact that Sande wanted to do camp again the second year was a testament to how well it went the first year.

Sandra: I chuckled when I read Robin's reflective description of how well the camp went the first year. It was a struggle in two regards. The Shawnee elder and her family ran all of the cultural activities and this was great as we (the students or myself) do not have the cultural knowledge or expertise to teach these segments. While their focus was on teaching these activities, they were also in charge of the overall flow and rhythm of the activities; the structure of the camp. This was an area with which the Miami students could assist, but there were not enough of them. While three students and myself went that year, only two were there for the entire camp. And two overnights were scheduled. In other words, two students--Casey and Jason--were the primary caretakers of the youth for four days with two overnights. It was too much for them. Driving home after camp we were all exhausted and I'm not sure at that point any of us would have said the camp went well! But, I was certain we could do it again and do a much better job, particularly with more students and a clearer definition of roles.

The second year, the planning phase of the program was handled by one team as part of the AMS 301 course. The elders did not return, but local elders from the tribe taught the cultural component. There was consistent, regular communication between Robin and the group and that was helpful. Five students from Miami registered and participated in the camp and the increased number of counselors helped relieve a lot of the stress. Throughout the semester these students researched and practiced leading numerous filler, team-bonding activities, which also really helped with the flow of the camp. Camp was extended from four 
to five days and there was only one overnight stay. Twenty-two ESTOO youth participated and we asked three of the oldest males to participate as junior counselors. This was good as they then felt more invested in the program.

\section{Reflections on Camp}

Robin: Kids don't come around to the tribe that much, but they look forward to camp. We had a lot of repeat campers this year, which serves as a testament to the camp. It was really wonderful having college students as counselors. The age of the college students and their cultural sensitivity was a really good mix. The students were able to relate well with the campers. Because of their closeness in age, they had similar interests with the campers and were able to identify the kid's needs while at the same time being respectful of the camper's ESTOO culture. It was also great that the Miami students had an interest and brought their talents. We did not necessarily have those resources, so it was nice that students were able to bring their individual skills. For example, there was a young woman who played collegiate lacrosse who was able to help teach the campers the game in a way that we would not have been able to.

Jason: Attending the summer workshop for two years helped me to grow personally and to develop an appreciation for modern ESTOO culture. My first trip to Oklahoma was humbling. I arrived believing I was well versed in Shawnee culture after researching it for a whole semester. Upon arrival, I was disappointed to discover that ESTOO people were not like the static portraits of their ancestors in the histories that I read. I struggled to reconcile the images that I saw in history books with the ESTOO youth that I was working with. I now know that it was ignorant of me to hold this romanticized view of ESTOO. ESTOO culture still lives on, but not in the way that I imagined. Returning to camp the second year helped me to understand that it is not my place to decide what is and what is not authentic ESTOO culture. It is ESTOO's right to develop their identity and to tell their own stories. Visiting ESTOO definitely helped me to understand, respect, and appreciate ESTOO as they see themselves presently.

Sandra: The camp experience was much better the second year due to the larger number of Miami participants and our greater familiarity with one another. Jason makes a point that I think is an important one and underpins what I think is so important for Miami University students to have these sorts of experiences. The traditional classroom setting is seriously limited for providing students with opportunities for intercultural dialogue and understanding. It takes personal exposure for students to begin to grasp in a real world experience those concepts that they may seem to grasp intellectually. Jason is not the only student to have this experience.

This year an incident occurred on the first day of camp when a student dressed in a tank top-the temperature was in the mid-nineties, and this student was working with ESTOO youth on lacrosse. It did not occur to me that her attire might be considered inappropriate by 
community members as it was not out of line from what I'm used to seeing on the college campus and it was hot. At the end of the day, Robin pulled me aside and expressed that the top was considered too revealing and that Native values promoted modesty. Robin asked if I wanted her to communicate this with the student or if would I prefer her to do so.

Robin: Communicating the Native, cultural value of modesty became an issue when one female university student wore a tank top considered to be too revealing and not considered to be congruent with the ESTOO value of modesty. I notified Sande and she was able to talk to the student. This was a cultural teaching moment. $\mathbf{S G}$ : I agreed to talk to the student in private. It was an awkward and emotional conversation as the student was hurt, embarrassed, and defensive. She described how for many years she had worked to deal with issues around her body image and was just beginning "to feel comfortable in her skin." Why, she asked me, did she have to change her values and norms in order to conform to those of the ESTOO?

\section{Concluding Thoughts}

Jason: Working on numerous projects with ESTOO exceeded my expectations primarily because I was able to travel out to Oklahoma and see the importance and the effects of the projects. Knowing that my research has meaning and having the opportunity to meet the community it serves is highly motivating. It was really impactful for me to realize that my research was about more than a letter grade. Seeing how my research positively contributed to the ESTOO community helped me to understand the power of research on a deeper level. Research can be about much more than writing a term paper. It can be more than a grade; it can be an idea that can eventually affect a community. You are giving life to past history and it is finally being applied into the world once again. Maybe this is why it was difficult for me to let go of a project since I had nurtured and collaborated on it for countless hours for someone else to try and interpret its significance.

Casey: ESTOO invited me to share in the story and history of their community and in doing so helped me to begin to identify and articulate my own personal story and purpose. It is in large part due to my experiences working with ESTOO that I developed an interest in community driven projects and research and that I am pursuing a master's degree in Student Affairs in Higher Education at Miami University. I am looking forward to continuing to work with ESTOO and it is my hope that as a student affairs professional that I can empower students, as Dr. Garner empowered me, to serve diverse communities in a very authentic and productive way.

Robin: The relationship has addressed our needs very, very well. We learned from the students and they learned from us. The relationship was reciprocal; we were able to enrich the students' lives and they were able to enrich our lives. This year we had a stomp dance and the college students were able to participate in the dance, and I think that they left with a deeper understanding and appreciation for ESTOO culture. They participated with us. We want and 
are happy to share this culture with anyone, especially with the people that help us

One gentleman on business council has twin boys who attended camp. He is not one to volunteer praise but was happy and impressed that Jason and Brooke came back, allowing for consistency with counselors. They were glad to have Jason back. It was the consistency that impressed - that Jason and Brooke returned after graduation was a personal commitment that wasn't mandated-it was a true giving of the spirit. This relationship was a godsend and I'm really looking forward to seeing where it goes.

Sandra: Each year I can see tremendous progress in terms of the work being done in both the AMS 301 course and summer workshop. Building long-term relationships is the key and it requires time and patience. I do worry that the consistency of returning students is difficult to maintain, for the camp in particular; Miami students are only here for four years and I usually do not have interaction with the students for this class until their third or fourth year. That students have returned is testament to the sense of accomplishment that they receive from their efforts. I am concerned about the long-term viability of the workshop from the institutional perspective (Miami), where it is getting more and more difficult to keep courses on the books with a handful of students. If I had twenty students register for the summer workshop, I wouldn't know what to do with them. So keeping the numbers of responsible students at a level that facilitates the camp in balance with the numbers required by the university to have the course is a tight-wire balancing act. I do get the opportunity with my long-term relationship to see the value of it for my students and ESTOO. We still have a great deal to learn, but are willing to do so.

\section{About the Authors}

Robin Dushane is the tribal historic preservation officer for the Eastern Shawnee Tribe of Oklahoma, a position she has held for more than ten years.

Sandra Garner, (corresponding author) is an assistant professor in the department of Global and Intercultural Studies teaching primarily for the American Studies major. Her broad research and teaching interests focus on culture, specifically issues of identity and, intercultural awareness and understanding-particularly the construct of Indigenous identities emergent from settler colonial contexts. She is the author of To Come to a Better Understanding: Medicine Men and Clergy Meetings on the Rosebud Reservation, 1973-1978, which examines the possibilities and limits of intercultural understanding (2016).Garners2@miamioh.edu 
Casey Smitson is a Miami University alumni (2014), served as a Fulbright English Teaching Assistant Düsseldorf, Germany (2016) and currently pursuing her master's degree in Student Affairs in Higher Education at Miami University.

Jason Banks is a Miami University alumni (2015) and plans to pursue a graduate degree in Public Policy.

\section{References}

Deloria, V. (1969). Custer died for your sins; an Indian manifesto. New York: Macmillan.

Smith, L. T. (1999). Decolonizing methodologies: research and Indigenous peoples. London and New York: Zed Books. 